\title{
Retraction Note to: Pressure Transient Analysis for Multi-stage Fractured Horizontal Wells in Shale Gas Reservoirs
}

\author{
Jingjing Guo ${ }^{1} \cdot$ Liehui Zhang $^{1}$ - Haitao Wang ${ }^{1}$ • \\ Guoqing Feng ${ }^{1}$
}

Published online: 30 April 2015

(C) Springer Science+Business Media Dordrecht 2015

\section{Retraction Note to: Transp Porous Med (2014) 93:635-653 DOI 10.1007/s11242-012-9973-4; Transp Porous Med (2015) 106:707 DOI 10.1007/s11242-014-0439-8}

The reason for retraction stated was not complete. The correct text is as follows:

This article has been retracted at the request of the Editor-in-Chief. The article contains the same research approach and results including similar mistakes as the article published in Journal of Petroleum Science and Engineering: Zhao, Y., Zhang, L., Wu, F.: Pressure Transient Analysis for Multi-fractured Horizontal Well in Shale Gas Reservoirs, 2012, vols. 90-91, pp. 31-38. This article has also been retracted http://www.sciencedirect.com/science/article/ pii/S0920410512000897.

Both papers were simultaneously submitted to the two journals by the same corresponding author, omitting any referral to the other paper.

The publisher apologizes for any inconvenience this may cause.

The online version of the original article can be found under doi:10.1007/s11242-012-9973-4.

Liehui Zhang

zhangliehui@vip.163.com

1 State Key Laboratory of Oil and Gas Reservoir Geology and Exploitation, Southwest Petroleum University, 8 Xindu Avenue, Xindu District, Chengdu 610500, People's Republic of China 